\title{
EDITORIAL
}

\section{Authors' responsibilities: guidance for submission of manuscripts to medical journals}

\section{See correction by Szeinbach on page 257}

This Journal recently published a paper ${ }^{1}$ which, unknown to the editors - there was no author declaration of any previous related publication - presented an analysis of data previously used to answer a different research question in an earlier paper $^{2}$ published in another journal, the Annals of Allergy, Asthma and Immunology. It is perfectly acceptable to use the same dataset in order to answer different research questions, and perfectly acceptable to present the results of any new analysis as a separate research paper - as was the declared aim in this instance. However, it is the responsibility of authors to ensure that previous publications, particularly those using the same dataset, are cross-referenced when reporting. This did not occur in this instance, and resulted in a third-party complaint to the editors of both journals concerned. A full investigation ensued, involving the Editor-in-Chief, Deputy Editor, Assistant Editors and publishers of the Primary Care Respiratory Journal (PCRJ), and the Editor-in-Chief of the Annals of Allergy, Asthma and Immunology (AAAI).

We have concluded that the paper submitted to the PCRJ was not a duplicate publication in terms of the study aims and outcomes. However, there is no doubt that substantial parts of the text of the PCRJ paper - including parts of the introduction, methods, results and discussion sections - are extremely similar to the paper published previously in the AAAI. In addition, the authors had not declared to the editors (and therefore the referees) of the PCRJ the fact that the AAAI paper - in which they had used the same dataset - had been published. Furthermore, in not referencing the AAAI paper they did not permit readers of the PCRJ to put the later PCRJ paper in context. A correction is published in this issue of the PCRJ. ${ }^{3}$

Both journals have liaised with Medline/PubMed regarding the appropriate way to deal with this situation. The result is this published editorial highlighting the linked publications. A similar editorial will be published in the AAAI. We also wish in this editorial to draw the attention of future authors to the requirements relating to, and the ethics of, the submission of manuscripts for publication in medical journals.

Guidance for the publication of research papers in biomedical journals is clearly laid down in the document 'Uniform Requirements for Manuscripts Submitted to Biomedical Journals: Writing and Editing for Biomedical Publication' on the International Committee of Medical Journal Editors' (ICMJE) website. ${ }^{4}$ Further guidance is available from the World Association of Medical Editors (WAME) in their document on publication ethics policies. ${ }^{5}$ Most medical journals listed on scientific databases (such as Medline/PubMed, EMBASE/Exerpta Medica and Scopus) subscribe to these principles which are detailed in their documentation on 'guidance for authors'.

It would seem that some authors are unfamiliar with these guidelines, in particular the section relating to redundant (or duplicate) publication. Duplicate publication is defined as "publication of a paper that overlaps substantially with one already published in print or electronic media". Most medical journals will not accept duplicate publications, unless these are translations of important documents - guidelines for example - that would benefit from wider distribution. According to the ICMJE guidelines; ${ }^{4}$ " ... when submitting a paper, the author must always make a full statement to the editor about all submissions and previous reports that might be regarded as redundant or duplicate publication of the same or very similar work. The author must alert the editor if the manuscript includes subjects about which the authors have published a previous report or have submitted a related report to another publication. Any such report must be referred to and referenced in the new paper. Copies of such material should be included with the submitted paper to help the editor decide how to handle the matter."

Duplicate or 'redundant' publication may manifest in a variety of ways; these have been highlighted in an analysis of systematic reviews, in which six different patterns of duplicate publication are described. ${ }^{5}$ These range from exact replication, to the reproduction of sections of text without detailed cross-referencing within manuscripts.

It is the responsibility of authors to be aware of published guidance on the requirements for manuscripts submitted to medical journals, and to read carefully and understand the legal documents which they sign when submitting papers for publication. 


\section{References}

1. Szeinbach SL, Seoane-Vazquez EC, Beyer A, Williams PB. The impact of allergic rhinitis on work productivity. Prim Care Resp J 2007;16(2):98-105. doi:10.3132/pcrj.2007.00015

2. Szeinbach SL, Williams PB, Kucukarslan S, Elhefni H. Influence of patient care provider on patient health outcomes in allergic rhinitis. Ann of Allergy, Asthma and Immunol 2005;95(2):167-74.

3. Correction. Szeinbach SL. Prim Care Resp J 2007; 16(4):257. doi:10.3132/pcrj. 2007.00051

4. Uniform Requirements for Manuscripts Submitted to Biomedical Journals: Writing and Editing for Biomedical Publication' on the International Committee of Medical Journal Editors http://www.icmje.org/ (accessed 28th May 2007).

5. WAME Recommendations on Publication Ethics Policies for Medical Journals . http://www.wame.org/resources/publication-ethics-policies-for-medicaljournals\#orig (accessed 28th May 2007).

6. Erik von Elm, Greta Poglia, Bernhard Walder, Martin R Tramer. Different Patterns of Duplicate Publication: An Analysis of Articles Used in Systematic Reviews. JAMA 2004;291:974-80.

\section{*Mark L Levy}

Editor-in-Chief, Primary Care Respiratory Journal; Senior Clinical Research Fellow, Allergy and Respiratory Research Group,

Division of Community Health Sciences: GP Section, University of Edinburgh, UK.

\section{Gailen D Marshall}

Editor-in-Chief, Annals of Allergy, Asthma and Immunology; Professor of Medicine and Pediatrics, Vice Chair for Faculty Development, Director, Division of Clinical Immunology and Allergy, The University of Mississippi Medical Center, 2500 North State Street Jackson, MS 39216-4505, USA.

\section{*Correspondence:}

c/o GPIAG, Smithy House, Waterbeck, Lockerbie, DG11 3EY, UK. Tel: +44 (0)1461 600639 Fax: +44 (0)1461 207819

E-mail: marklevy@animalswild.com

28th June 2007

\section{Available online at http://www.theprj.org}

